\title{
Role model: Tamsin Greenwell
}

\author{
The consultant urologist tells Helen Jones how she came to choose her specialty and about the \\ variety it offers
}

\section{Helen Jones}

London, UK

Tamsin Greenwell, a consultant urologist and honorary associate professor at University College London, was originally going to study civil engineering at university.

"I wanted to build dams," she says. "But then I took a gap year, became friendly with some medical students, and realised that what they were doing was people centred, intellectually stimulating, challenging, and a much better fit."

Greenwell studied medicine at Manchester University which she chose "because it was the largest medical school in the UK offering significant diversity" and also "because of the city's great music scene."

This was followed by a move to Sheffield for research and specialty training, and then finally to London. "My husband is an orthopaedic spinal surgeon and we felt that London would give us the best opportunity to work somewhere that wasn't miles away from each other," she says.

Initially, Greenwell considered specialising in gynaecological oncology, but when she covered urology at a house job at Salford Royal Infirmary she found herself drawn to the specialty. "I thought the urologists were amazing. They were so kind and accessible—and, importantly, happy," she explains. "I also found their patients and the work really interesting."

In her current role, every day is different. "I have one all day outpatient clinic and two all day theatre lists as well as multidisciplinary team meetings and administrative commitments," Greenwell says.

"I particularly enjoy my theatre days-seeing patients beforehand, operating, and taking my trainees through operations, then talking to patients afterwards. It's always interesting, never boring, and, occasionally, scary."

Greenwell combines her consultant role with teaching and has been the urology tutor for the Royal College of Surgeons and director of education for the British Association of Urological Surgeons.

"It's about making sure that in their short training period, and within their overcrowded working lives, we can optimise trainees' practice and practical skills as well as help and support them," she says.

She adds, "Students don't get enough urology at medical school and it's not considered as a career option by many trainees. I wholeheartedly recommend it as there is a great mix of endoscopic, open, and robotic surgery. There are not that many urological emergencies, so it's not as busy overnight as other specialties and offers a reasonable work-life balance."

Greenwell manages to combine her workload with family and a range of exercise classes. "It's important to me to stay fit and mobile so I can continue working productively," she says.

She also has a significant interest in shoes and has over 100 pairs. "I'm not sure if 'shoe collecting' is officially a hobby but perhaps it should be," she says.

\section{Nominated by Rachel Barratt \\ Over her career, Miss Greenwell has developed a specialist unit that provides surgical options for rare conditions including urethrovaginal fistulas, urethral strictures, and urethral diverticulectomy. This has given patients with uncommon problems access to procedures, performed in a high volume setting, which drastically improve their quality of life. \\ Inherently, this type of service can present challenges but Miss Greenwell's dedication to constant improvement ensures that they are met, enabling the unit to improve year on year. \\ Alongside her clinical and surgical skills, she is passionate about the training of future urologists. Miss Greenwell finds time to present and write up research as well as contributing to national and international meetings. She is a compelling speaker and always seems to win a debate. \\ In her day to day working life she mixes professionalism with a good dose of fun and laughter. Her work ethic and dedication to improving female and functional urological services for patients in the NHS are truly inspirational. Rachel Barratt is a urology registrar at University College Hospital}

To nominate someone who has been a role model during your medical career, send their name, job title, and the reason for your nomination to arimmer@bmj.com Published by the BMJ Publishing Group Limited. For permission to use (where not already granted under a licence) please go to http://group.bmj.com/group/rights-licensing/ permissions 